\title{
Effectiveness of Musculoskeletal Emergency Physiotherapy Practitioners
}

\author{
Emma Salt \\ Physiotherapy Department, Queen's Hospital Foundation Trust, Burton on Trent, UK \\ Email: emma.salt@nhs.net
}

Received 25 May 2016; accepted 31 July 2016; published 3 August 2016

Copyright (C) 2016 by author and Scientific Research Publishing Inc.

This work is licensed under the Creative Commons Attribution International License (CC BY). http://creativecommons.org/licenses/by/4.0/

(c) (i) Open Access

\begin{abstract}
Relevance and Method: The purpose of this project was to evaluate the effectiveness of the Emergency Physiotherapy Practitioner (EPP) service against quality care indicators identified as part of the "gold standard" for emergency care in England. The study was prospective and evaluated time to initial assessment, total time in the emergency department and un-planned re-attendance rate within a seven-day period for all patients seen by the EPP's over a period of one year. Outcomes: One thousand and seven patients were seen by EPPs in the emergency department. The median wait time for treatment by an EPP was 34.5 minutes (95th percentile $=122$ ). Regional median wait time was 45 minutes $(95$ th percentile $=138$ ). National median wait time was 55 minutes $(95$ th percentile $=192$ ). Median total time spent in ED for patients seen by EPPs was 99 minutes (95th percentile $=224$ ). Regional median total time in ED was 223 (95th percentile $=239$ ). Nationally median total time in ED was 136 minutes $(95$ th percentile $=336$ ). Three percent of patients seen by an EPP returned to the ED, compared to $6 \%$ regionally and $7.5 \%$ nationally. Conclusions: EPPs excelled in all three indicators and exceeded regional and national figures. The re-return rate met the current standard of being less than $5 \%$. It could be justified that the addition of the EPPs to the emergency department was an efficient and effective service development.
\end{abstract}

\section{Keywords}

Musculoskeletal, Physiotherapy, Emergency Care

\section{Introduction}

Growth in the number of people using urgent and emergency care is leading to mounting costs and increased pressure on resources [1]. In the United Kingdom, £440 million pounds was spent on management of musculoskeletal injuries in emergency departments in 2012-2013 [2]. 
Musculoskeletal Emergency Physiotherapy Practitioners (EPPs) can work as frontline healthcare providers for patients who attend Emergency Departments (EDs). They can work independently from medical and nursing staff, undertaking expert patient management for patients attending emergency and accident departments with musculoskeletal dysfunction. Integration of EPPs in EDs has been reported to improve patient outcomes [3]-[7], improve patient flow [7]-[9], streamline care without additional use of resources such as use of radiographic investigation [4] [10], reduce costs [4] and improve patient satisfaction [1] [4] [5] [7] [9].

An initial pilot was conducted in 2012 in the ED of a hospital in the West Midlands, England, to establish how feasible an EPP service would be in a moderately sized acute hospital. Promising initial results from that pilot led to the development of a service provision of musculoskeletal EPP physiotherapists in the emergency department in 2013.

In 2011/12, The Operating Framework for the NHS [11], England announced a set of clinical quality indicators around which emergency care should be delivered. The purpose of this project was to evaluate the EPP service against these quality indicators.

\section{Methods}

A prospective study was conducted in the emergency department of an acute hospital (classified as a major centre for emergency care) in the West Midlands, England, over the period of one year. The mean number of annual emergency department attendances at this hospital site is 112,000 . Planned outcomes included three quality indicators: time to initial assessment, total time spent in emergency departments and unplanned re-attendance rates within a 7-day period for all patients who had been seen by EPPs in the emergency department in 2014. Data was captured using an automated electronic data system (Meditech version 5 EPR system) at the hospital. Ethical clearance and informed consent were not obtained due to this project being classed as a service evaluation. Service evaluations do not randomise patients, use any inclusion or exclusion criteria, or require research ethical approval or patient consent [12].

Statistics were evaluated using median values with 95th percentiles for waiting time to treatment and total time in ED. Patients who re-returned to the ED were expressed as a percentage of total numbers seen. This method of evaluation was to enable a comparison of the EPPs to regional (total ED workforce within the hospital) and national figures, published by The Health and Social Care Information Centre. All analyses were computed using Microsoft Excel 2010.

\section{Results}

One thousand and seven patients were seen by one of three EPPs in the ED. All EPPs were senior physiotherapists (Two were band 7 and one band 8a on a UK pay structure) who were specialized in emergency care. They practiced autonomously which included the assessment and diagnosis of patients without the need for medical or nursing assistance. The physiotherapists were able to refer patients for relevant investigations to assist diagnosis such as X-rays and bloods. All patents data were available for analyses.

\subsection{Waiting Time to Treatment and Total Time in ED}

The median wait time for treatment by an EPP was 34.5 minutes (95th percentile $=122$ ). Median times for patients waiting to see an EPP were 10 minutes less when compared with local comparisons and 20 minutes less than national median wait times (see Table 1).

Table 1. Comparison between study group with local and national figures for waiting times to treatment and total time in ED.

\begin{tabular}{cccc}
\hline & \multicolumn{3}{c}{ Comparator groups (expressed as median values with $95^{\text {th }}$ percentile) } \\
& EPP in ED (study group) & Local Trust ED (local comparison) & England ED (national comparison) \\
\hline $\begin{array}{c}\text { Waiting time to } \\
\text { treatment (minutes) } \\
\begin{array}{c}\text { Total time in ED } \\
\text { (minutes) }\end{array}\end{array}$ & $34.5(122)$ & $45(138)^{\mathrm{a}}$ & $55(192)^{\mathrm{a}}$ \\
& $99(224)$ & $223(239)^{\mathrm{a}}$ & $136(336)^{\mathrm{a}}$ \\
\hline
\end{tabular}

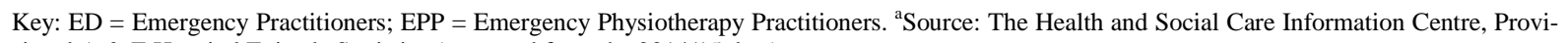
sional A \& E Hospital Episode Statistics (extracted from the 2014/15 data). 
Median total time spent in ED for patients seen by EPPs was 99 minutes (95th percentile = 224), which was 124 minutes (more than two hours) less when compared to local median figures and 37 minutes less when compared to National median figures (see Table 1).

\subsection{Re-Attendance Rate in ED}

Three per cent of patients seen by an EPP returned to the ED, compared to 6\% regionally and $7.5 \%$ nationally (see Figure 1).

\section{Discussion}

Findings of this study with regard to waiting time to treatment and total time in ED are consistent with reports from other similar studies [6] [7], strengthening the likelihood that the incorporation of EPPs in ED can have a positive effect on reducing time for patients with musculoskeletal problems who can be seen by the EPPs. In addition, by enabling the EPPs to see many of the patients with musculoskeletal problems, other ED practitioners, such as medical and nursing staff can be available to manage patients attending ED with non-musculoskeletal dysfunctions, thereby having the potential to benefit all patients attending an ED.

This is the first study to evaluate re-attendance markers. The purpose of this indicator is to reduce avoidable re-attendances in ED by improving the care and communication delivered during the first attendance. Re-attendance has been recognized as a key quality indicator of effective clinical intervention. Good practice for unplanned re-attendance rates should be less than $5 \%$. This study indicates that this can be achieved by the addition of EPPs to an ED.

There are some limitations of this study: The study was conducted at only one hospital Trust and therefore is not generalizable. The same patients that were in the EPP data are also included in the local trust data, and the local trust data is incorporated into the national statistical data, meaning that comparisons can at best be an indication of differences rather than a true representation of differences. The study design was a service evaluation. Whilst service evaluations are beneficial in providing an understanding of the effectiveness of a new service, they are limited to representing the effectiveness only of the service where the study was conducted.

\section{Conclusion}

This study provides some evidence that the introduction of musculoskeletal EPPs into an emergency department can lead to improved quality of patient care. The main limitations relate to the design of the study; therefore further studies in the form of RCTs to compare effectiveness of EPPs on unplanned re-return rates are indicated.

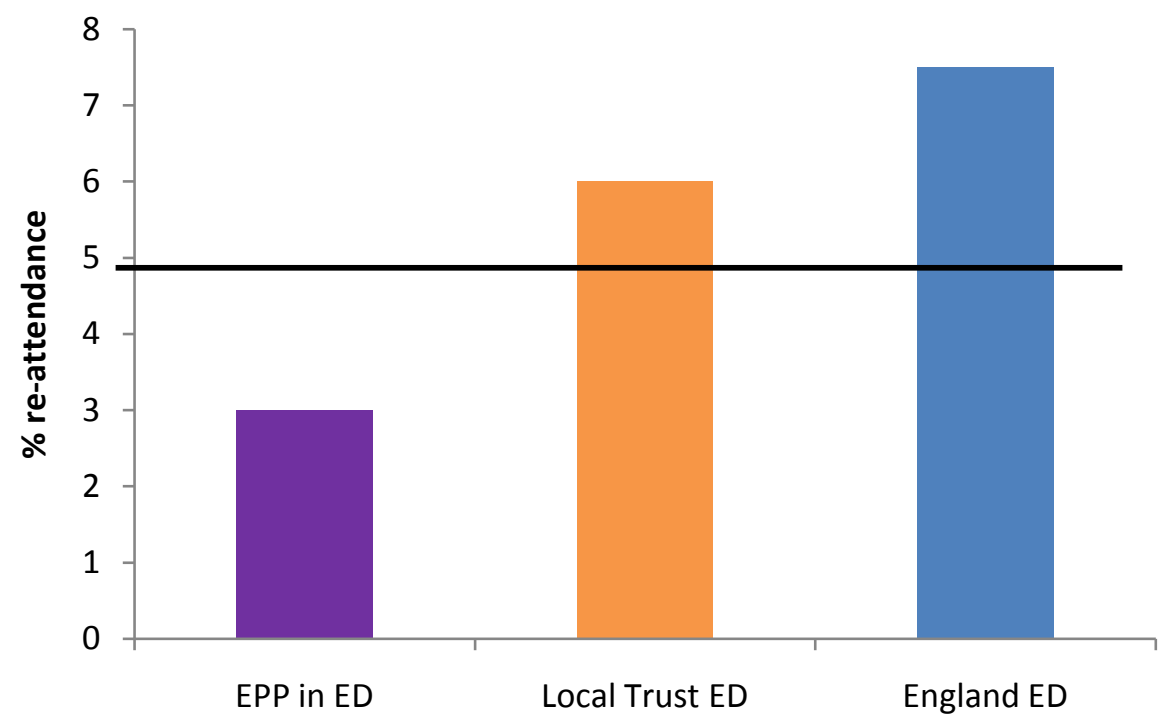

Figure 1. Unplanned re-attendance rates. Key: ED = Emergency Practitioners; EPP = Emergency Physiotherapy Practitioners. Footnote: Horizontal black line represents the 5\% standard of "good practice". 


\section{Acknowledgements}

Thanks are given to Manni Imiavan for support with the data capture and to Rachel McKeown and James Crampton for support with this project.

\section{References}

[1] McClellan, C.M., Cramp, F., Powell, J. and Benger, J.R. (2010) Extended Scope Physiotherapists in the Emergency Department: A Literature Review. Physical Therapy Reviews, 15, 106-111. http://dx.doi.org/10.1179/174328810X12719009060344

[2] Department of Health (DoH) National Schedule of Reference Costs 2012-13 for NHS Trusts and NHS Foundation Trusts. November 2013. https://www.gov.uk/government/publications/nhs-reference-costs-2012-to-2013

[3] McClellan, C.M., Greenwood, R. and Benger, J.R. (2006) Effect of an Extended Scope Physiotherapy Service on Patient Satisfaction and the Outcome of Soft Tissue Injuries in an Adult Emergency Department. Emergency Medicine Journal, 23, 384-387. http://dx.doi.org/10.1136/emj.2005.029231

[4] McClellan, C.M., Cramp, F., Powell, J. and Benger, J.R. (2012) A Randomized Trial Comparing the Clinical Effectiveness of Different Emergency Department Healthcare Professionals in Soft Tissue Injury Management. BMJ Open, 2, e001092. http://bmjopen.bmj.com/content/2/6/e001092.full http://dx.doi.org/10.1136/bmjopen-2012-001092

[5] Lau, P.M.-Y., Chow, D.H.-K. and Pope, M.H. (2008) Early Physiotherapy Intervention in an Accident and Emergency Department Reduces Pain and Improves Satisfaction for Patients with Acute Low Back Pain: A Randomized Trial. Australian Journal of Physiotherapy, 54, 243-249. http://dx.doi.org/10.1016/S0004-9514(08)70003-5

[6] Kilner, E. (2011) What Evidence Is There That a Physiotherapy Service in the Emergency Department Improves Health Outcomes? A Systematic Review. Journal of Health Services Research and Policy, 6, 51-58. http://dx.doi.org/10.1258/jhsrp.2010.009129

[7] Hussenbux, A., Morrisey, D., Joseph, C. and McClellan, C. (2015) Intermediate Care Pathways for Musculoskeletal Conditions-Are They Working? A Systematic Review. Physiotherapy, 101, 13-24. http://dx.doi.org/10.1016/j.physio.2014.08.004

[8] Taylor, N.F., Norman, E., Roddy, L., Tang, C., Pagram, A. and Hearn, K. (2011) Primary Contact Physiotherapy in Emergency Departments Can Reduce Length of Stay for Patients with Peripheral Musculoskeletal Injuries Compared with Secondary Contact Physiotherapy: A Prospective Non-Randomised Controlled Trial. Physiotherapy, 97, 107-114. http://dx.doi.org/10.1016/j.physio.2010.08.011

[9] Hoskins, R. (2010) Evaluating New Roles within Emergency Care: A Literature Review. International Emergency Nursing, 19, 125-140. http://www.sciencedirect.com/science/article/pii/S1755599X10000856 http://dx.doi.org/10.1016/j.ienj.2010.09.003

[10] Ball, S., Walton, K. and Hawes, S. (2007) Do Emergency Department Physiotherapy Practitioners, Emergency Nurse Practitioners and Doctors Investigate, Treat and Refer Patients with Closed Musculoskeletal Injuries Differently? Emergency Medicine Journal, 24, 185-188. http://dx.doi.org/10.1136/emj.2006.039537

[11] Operating Framework for the NHS England (2011) Emergency Department Clinical Quality Indicators: A CEM Guide to Implementation. http://www.collemergencymed.ac.uk/

[12] NHS Health Research Authority (2007) http://www.hra.nhs.uk/documents/2013/10/differentiating-audit-service-evaluation-and-research-version-1-1.pdf 


\section{Submit or recommend next manuscript to SCIRP and we will provide best service for you:}

Accepting pre-submission inquiries through Email, Facebook, LinkedIn, Twitter, etc.

A wide selection of journals (inclusive of 9 subjects, more than 200 journals)

Providing 24-hour high-quality service

User-friendly online submission system

Fair and swift peer-review system

Efficient typesetting and proofreading procedure

Display of the result of downloads and visits, as well as the number of cited articles

Maximum dissemination of your research work

Submit your manuscript at: http://papersubmission.scirp.org/ 